\title{
Editorial
}

\section{Gesund und glücklich}

_Sommer, Sonne, Ferienzeit - den einen verschlägt es ans Meer, andere gehen lieber zum Wandern in die Berge, fahren ein paar Tage raus aufs Land oder buchen einen Städtetrip.

_Allesamt übrigens gesundheitsfördernde Maßnahmen. Denn laut der Framingham-Herz-Studie tut die Auszeit vom Alltag gut: Wer länger nicht verreist, wird eher krank und stirbt früher, als jemand, der sich regelmäßig freinimmt. Dabei ist es nicht wichtig, möglichst lange Urlaub zu machen, sondern möglichst häufig.

_ Urlaub beugt nicht nur Krankheiten vor, sondern macht außerdem noch glücklich. Das hat die Arbeitspsychologin Dr. Jessica de Bloom erforscht. Einen Familienausflug oder einen Kurztrip zu unternehmen, macht glücklicher, als sich neue Kleidung oder ein Handy zu kaufen. Der Grund ist, dass man Erfahrungen nicht so einfach miteinander vergleichen kann - materielle Dinge hingegen schon. Außerdem, sagt de Bloom, verschleißen die eigenen Erlebnisse nicht.

_ Ich habe mir diese Studien zu Herzen genommen und werde ganz im Sinne der Gesundheitsförderung verreisen. Und wohin auch immer es Sie verschlägt, ich wünsche Ihnen eine tolle Urlaubszeit.

\section{Viel Spaß beim Glücklichwerden!}

Ihre
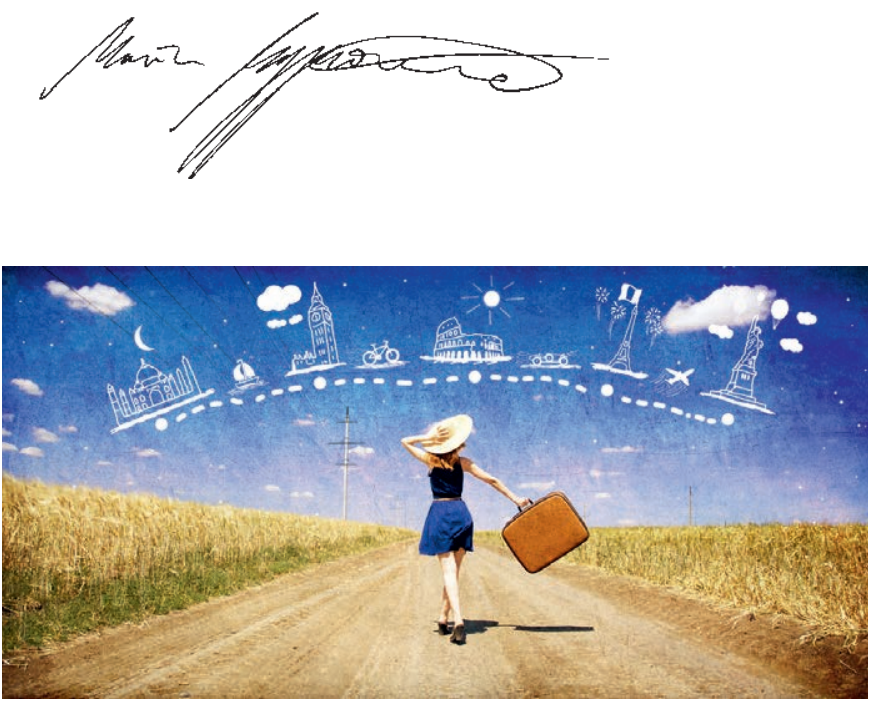

\section{ZU GEWIINNEN}

Kursplatz

1 Seminar „Borderline versus Gefühlen angemessenen Raum geben?“

Bücher

3-mal „Gesunde Ernährung bei Rheuma“ Seite 28 3-mal „Wie Gedanken unser Wohlbefinden beeinflussen" 2-mal „Ergotherapie im Arbeitsfeld Psychiatrie“ 1-mal „Kölner ApraxieScreening" 3-mal „Überraschend anders: Mädchen \& Frauen mit Asperger" 1-mal „100 Jahre Leben“ 3-mal „Persönlichkeit, Entscheidung, Verhalten“ Seite 58

und außerdem 1 Klangmemo 3 DVDs „Der Geschmack von Apfelkernen“" 